\title{
Gynecologic Issues in the Pediatric and Adolescent Patient with Cancer
}

\section{Gylynthia E. Trotman, MD MPH* Holly Hoefgen, MD}

\author{
Address \\ "Department of Obstetrics and Gynecology, Division of Pediatric and Adolescent \\ Gynecology, University of Cincinnati College of Medicine/Cincinnati Children's \\ Hospital Medical Center, 3333 Burnett Avenue MLC 2026, Cincinnati, OH, \\ 45229, USA \\ Email: Gylynthia.Trotman@cchmc.org
}

Published online: 19 July 2016

C Springer International Publishing AG 2016

This article is part of the Topical Collection on Pediatric Gynecology

Keywords Childhood cancer survivors · Fertility preservation - Menstrual and contraception management · Primary ovarian insufficiency $\cdot$ Acute ovarian failure $\cdot$ Sexual dysfunction

\section{Opinion statement}

Survival rates for children and adolescents with cancer have increased dramatically over the past 25 years. However, many of these therapies also result in short- and long-term adverse effects. In girls and young women, it is important to recognize the possible effects of oncologic treatments on their reproductive health and development including early or delayed puberty, diminished or complete loss of ovarian function, and infertility. There are several options for preserving fertility prior to cancer treatment that are becoming more readily available. The individual-planned treatments should be evaluated for risk of gonadal effects. This should be discussed with the patient and family in advance of starting treatment whenever possible, so they may reach an informed decision regarding fertility preservation. As with all adolescents, it is important to discuss issues of sexual health and contraception; however, this is especially important during active cancer treatment as available options may differ somewhat and individual cases must be evaluated. Finally, survivors of childhood cancer will need routine gynecologic evaluation and subsequent treatment of any ovarian insufficiency, infertility, and sexual dysfunction that occur as long-term effects of cancer care. This care is best accomplished in conjunction with a pediatric endocrinologist and/or gynecologist.

\section{Introduction}

The incidence of cancer in females under the age of 20 in the USA is 17.7 cases per 100,000 persons per year $[1 \bullet \bullet]$. Significant advancements in cancer therapies have led to an improvement in survival 
with the 5-year relative survival rate for females in this age group approaching $85 \%[1 \bullet \bullet]$. As a result, it is estimated that there are more than 100,000 females under the age of 20 living with a malignancy and over 380,000 survivors of childhood cancers in the USA $[1 \bullet \bullet, 2]$. The impact of cancer and cancer therapies can lead to an increase in both immediate and delayed adverse reproductive health outcomes [2, 3]. Here, we discuss common gynecologic concerns in the pediatric and adolescent patient with cancer.

\section{Cancer therapy}

\section{Chemotherapy/radiation}

The use of multi-agent chemotherapy and/or radiation in treatment of childhood cancers is common. The ovary is particularly sensitive to the adverse effects of cancer treatments due to the finite number of oocytes [4]. Although females are born with about 1-2 million primordial follicles, by puberty, only about 300,000 to 500,000 follicles remain which continually undergo a process of recruitment, atresia, and apoptosis $[5,6]$. Cancer treatment can accelerate the depletion of these oocytes [5]. This in turn may lead to ovarian insufficiency or failure, which may result in a temporary or permanent effect on both endocrine function of the ovary and reproductive capacity [7].

The risk of ovarian toxicity is proportional to patient age and pubertal status with younger girls less susceptible due to higher oocyte stores [8]. The type and dose of chemotherapeutic agent or radiotherapy, total radiation dose, and field involved are all factors in immediate and delayed effects [3]. Chemotherapeutic regimens containing alkylating agents are known to be particularly gonadotoxic even in pre-pubertal girls [8, 9]. Exposure to abdominal, pelvic, or spinal irradiation increases the risk of ovarian gonadotoxicity if the ovaries are in the radiation field, and cranial radiation may result in disruption of the hypothalamic-pituitary-ovarian axis (HPO) $[3,9]$. In addition to the gonadotoxic effects, pelvic radiation doses of greater than $5 \mathrm{~Gy}$ may compromise uterine and endometrial growth, particularly at younger ages. This further increases the risk of infertility and pregnancy complications $[5,8]$.

\section{Surgery}

Surgical resection of the reproductive organs to treat pelvic malignancies can result in loss of ovarian function and/or infertility [3]. Additionally, cranial surgery can lead to a dysregulation of the HPO axis and later to endocrine dysfunction.

\section{Pubertal concerns}

\section{Precocious puberty}

Precocious puberty (PP) is defined as the onset of breast development before age 8 years in girls [10-12]. Although there is controversy regarding the onset of puberty between ages 6-8 being normal, the validity of those recommendations have been continuously questioned [10-13]. As such, it is recommended that pubertal development in girls younger than age 8 years of age should be evaluated to avoid missing potential pathology [14, 15].

Central precocious puberty (CPP) results from early maturation of the HPO axis and occurs in those who have lost inhibition of hypothalamic gonadotropinreleasing hormone $(\mathrm{GnRH})$ release as a result of tumor presence, raised intracranial pressure, cranial surgery, or cranial irradiation [15-17]. Radiation dose of greater than $18 \mathrm{~Gy}$ and younger age at treatment are risk factors for CPP in the survivor [17]. Additionally, peripheral precocious puberty independent of GnRH secretion may result from estrogen-secreting ovarian tumors such as granulosa cell tumors [15]. The primary concern of PP is rapid bone maturation with a resulting reduced adult height; however, other long-term consequences include increased risk of reproductive cancers, metabolic syndrome, increased stress and anxiety, and negative psychosocial consequences [15, 18]. Peripheral PP as a result of malignant estrogen-secreting tumors is treated with surgical removal of the tumor. The decision to proceed with treatment of CPP is individualized and based on considerations of final adult height and psychosocial influences [15].

CPP is treated with GnRH agonists (GnRHa) which can also be initiated before or during cancer therapy if indicated. This medication acts to decrease pulsatile secretion of endogenous GnRH by providing constant serum levels of GnRH, which in turn leads to desensitization of $\mathrm{GnRH}$ receptors and gonadotrophin secretion $[11,15,19,20]$. 
There are several GnRH agonists available in the USA. Despite different routes of administration, dosing, and mechanism of action, they are all effective at treating CPP and individual selection should be tailored to the patient [19]. Treatment can be administered via daily subcutaneous injection or nasal spray, intramuscular injection every 4 or 12 weeks, or by sustained release yearly subcutaneous implant $[10,11,15,19]$. First-line treatment with longer-acting injectable GnRHa or subcutaneous implant should be considered due to adequate pubertal suppression with the additional benefit of fewer painful injections and facility visits which may aid with increased compliance and patient comfort [11, $19,21,22,23 \bullet]$. The 11.25-mg depot leuprolide 3month injection is used most frequently for this indication in the USA $[11,19,21]$. In addition, a recent study on the depot triptorelin embonate 22.5-mg 6-month injection has been reported and shows promise for a longer-acting extended injection regimen [23•]. The $50 \mathrm{mg}$ histrelin implant has emerged as a beneficial longer-acting option that may have benefits in pubertal suppression beyond the 1 year duration of use $[11,21$, $24 \bullet \bullet]$. This was supported by a study of 33 children with $\mathrm{CPP}$ in which equivalent rates of pubertal suppression were found in children who used a single rod for 12 or 24 months $[24 \bullet \bullet]$.

\section{Delayed puberty}

In the pre-pubertal or early pubertal girl, cancer and its therapy may alternatively result in delayed, interrupted, or absent puberty due to hypogonadism and result to low sex steroid production [3]. Central hypogonadism signaled by low follicle stimulating hormone (FSH) and luteinizing hormone (LH) can result from cranial tumors or as a result of high-dose cranial radiation (>30 Gy). Alternatively primary hypogonadism may result from direct gonadal toxicity due to therapeutic effects signaled by high FSH and LH levels [25]. Delayed puberty has negative implications for bone mineralization and psychosocial well-being [26]. Management in conjunction with a pediatric endocrinologist is important to insure appropriate pubertal development and initiation of sex steroid hormone replacement as needed. The goal of sex steroid replacement with estrogen is to optimize height and bone health while mimicking the normal pubertal progression of peers with slow and gradual increase in hormonal concentrations [26-29]. Cyclic progestin is later required for endometrial protection, and can be initiated prior to or after menarche, but only after substantial breast development [29, 30]. A variety of sex steroid replacement options for pubertal induction are available (Table 1) [26, 27]. However, studies are needed to determine the optimal delivery for pubertal induction [27].

\section{Acute ovarian failure and primary ovarian insufficiency}

Acute ovarian failure (AOF) is defined as loss of ovarian function within 5 years of treatment and is reported in about $6.3 \%$ of survivors $[8,31]$. AOF is more likely to occur with radiation doses greater than $10 \mathrm{~Gy}$, exposure to alkylating agents, and in older adolescents as younger ages are less susceptible due to higher oocyte stores [8, 31]. Female survivors who retain ovarian function are at higher risk of later developing primary ovarian insufficiency (POI) formerly called premature menopause, which is defined by the presence of menopausal-level serum gonadotropins in association with irregular menses in a woman younger than 40 years $[8,29,32]$. POI is the preferred term because ovarian function is often intermittent or unpredictable in many cases [29, 33]. The cumulative incidence of POI among cancer survivors is about $8 \%$ compared to sibling controls with a cumulative incidence of $<1 \%$ and the risk is highest for survivors treated with an alkylating agent plus abdominal-pelvic radiation with a cumulative risk approaching $30 \%$ [8]. POI adversely affects quality of life by increasing the risk of irregular/abnormal menses, psychosexual dysfunction, menopausal symptoms, infertility, ischemic heart disease, and osteoporosis $[3,8]$.

Hormone replacement therapy (HRT) with estrogen and progestin is needed to maintain bone, brain, and cardiovascular health and prevent other adverse effects (Table 1) [29]. Unlike pubertal induction, HRT for an adolescent with POI that has completed pubertal development can initiate full replacement dose of sex steroid hormones. Finally, as there is a $5-10 \%$ risk of conceiving among patients diagnosed with POI, barrier methods or intrauterine system (IUS) should be used for contraception [29, 34]. The levonorgestrel (LNG) containing IUS has the benefit of providing both endometrial protection and effective contraception.

\section{Fertility considerations and preservation options}

It is well established that survivors of childhood cancers are at increased risk of infertility which may be transient, permanent, or delayed $[8,35,36]$. The ability to have biological children is one of the most 


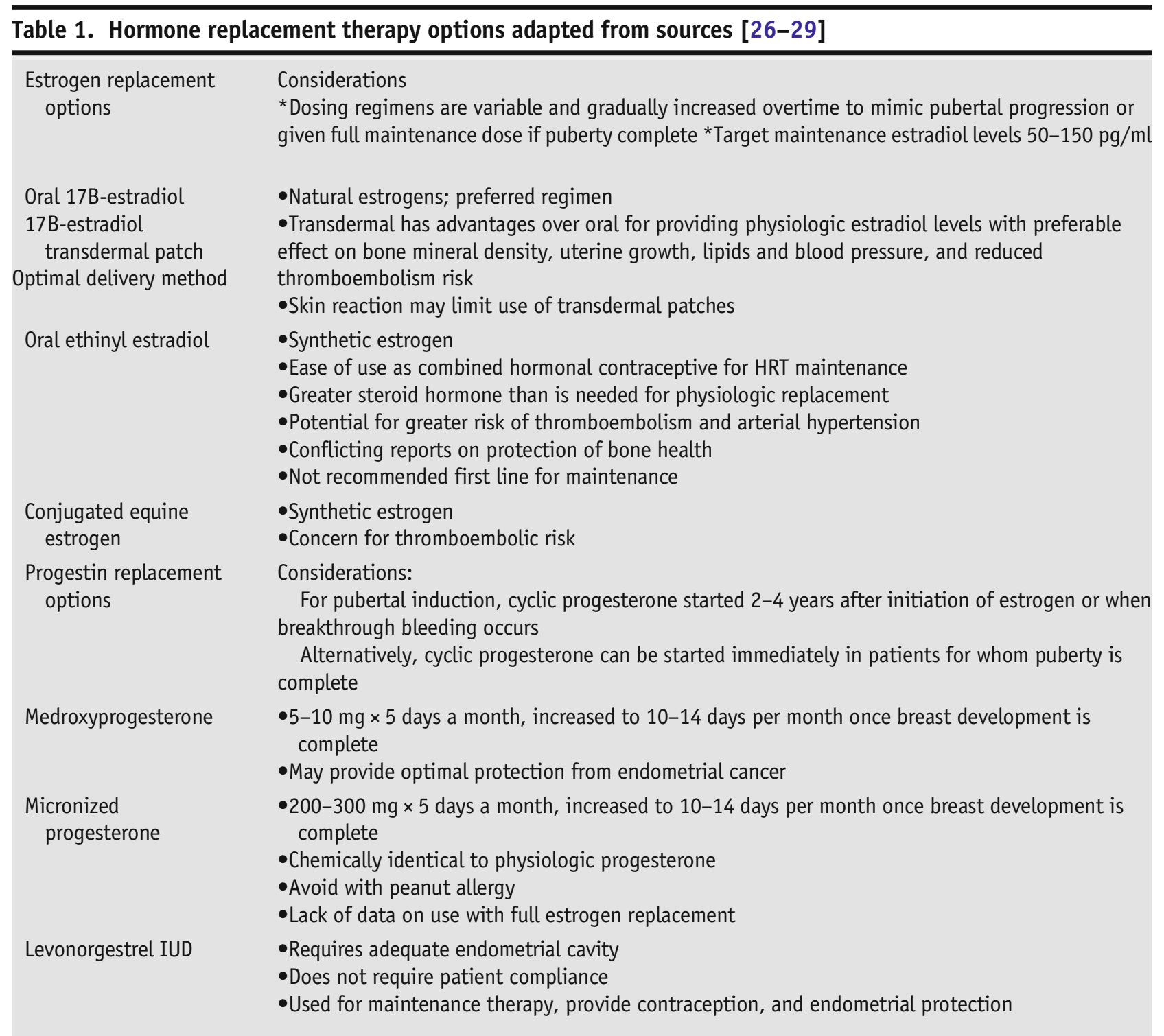

important quality of life issues in survivors of childhood cancers [4]. Both parents and patients are concerned about the risk of infertility related to cancer and its treatment [37]. Additionally, studies have shown that receiving specialized counseling about reproductive loss and pursuing fertility preservation is associated with less regret and greater quality of life for survivors [38]. The American Society of Clinical Oncology (ASCO), American Society of Reproductive Medicine (ASRM), and American Academy of Pediatrics (AAP) recommend clinicians to discuss risks to fertility and preservation options and make appropriate referrals to a reproductive specialist when needed prior to initiating treatment $[39 \bullet \bullet, 40 \bullet \bullet, 41]$.

\section{Fertility options}

Fertility preservation options depend on a variety of factors including patient age, diagnosis, risk of anticipated treatment, available time, and overall health of the patient $[25,39 \bullet \bullet]$. However, patients should also be counseled that no option can guarantee fertility. 


\section{0ocyte/embryo cryopreservation}

Both are established methods for young women and girls of reproductive age which involve controlled ovarian hyperstimulation and oocyte retrieval $[25,39 \bullet \bullet$, $40 \bullet \bullet, 42]$. Embryo cryopreservation is the most established method that provides a good success rate depending on the number and quality of embryos stored $[43,44 \bullet \bullet$. This method involves using sperm to immediately fertilize the oocyte followed by embryo freezing. It is generally not suitable for young women who do not have a partner and do not wish to use a sperm donor $[25,39 \bullet \bullet, 42]$. Oocyte cryopreservation, in which the oocytes are frozen without fertilization is favorable in the younger population [25]. Although there is less data on pregnancy and live birth rates, improvement in freezing and thawing techniques have led to improved success rates $[25,39 \bullet \bullet, 43,45,46]$. Both oocyte and embryo cryopreservation generally requires 2-4 weeks and may require a delay in cancer treatment which may not be possible given the diagnosis and medical status. Neither technique is suitable for prepubertal girls. However, controlled ovarian hyperstimulation and subsequent oocyte cryopreservation can be performed in peripubertal girls.

\section{Ovarian tissue cryopreservation}

Ovarian tissue cryopreservation (OTC) is an experimental option available only under study protocol for young women and post-pubertal girls unable or unwilling to undergo ovarian stimulation and is the only option for pre-pubertal girls $[4,39 \bullet \bullet]$. In this procedure, the entire ovary or a portion of the ovary is removed and the ovarian cortex containing the follicles is cryopreserved. The cryopreserved tissue is later re-implanted. At least 42 live births have been reported worldwide using ovarian tissue cryopreservation in patients who were pubertal at time of ovarian tissue cryopreservation [47]. Transplanted tissue may additionally restore hormonal function in addition to reproductive capacity; however, function is typically limited and has been shown to last 9 months to 3 years $[48,49]$. The safety of reimplantation of ovarian tissue has come into question as there is concern that ovarian tissue re-implantation may lead to reintroduction of cancer cells primarily with blood-borne cancers such as leukemia [50•]. Current research is investigating methods to mature and fertilize follicles in vitro without transplanting tissue, which may allow preservation of fertility without risking reintroduction of cancer cells [25]. At our institution, we have done over 50 OTC procedures to date.

\section{In vitro maturation}

In vitro maturation (IVM) is another experimental technique in which immature oocytes are retrieved with minimal or no ovarian stimulation and matured. The oocytes can then be cryopreserved with or without fertilization [43]. There is currently no available data on its use and efficacy in cancer patients and controversy exists regarding its place among other assisted reproductive techniques $[43,51]$.

\section{Ovarian transposition}

Ovarian transposition or oophoropexy can be utilized in patients undergoing high-dose radiation to the pelvis. The ovaries with or without the fallopian tube are moved ideally $>3 \mathrm{~cm}$ outside of the radiation field [25, 52]. Transposition can reduce the rate of radiation exposure 50-90\% [52]. However, its benefits in fertility preservation is debated as most studies evaluating success used return to menses as a surrogate marker for ovarian function, which gives little information on a woman's future reproductive and fertility potential. Furthermore, it does not protect the uterus from structural and vascular damage [25].

\section{GnRH agonist therapy}

GnRHa has been proposed as a method to preserve ovarian function by mimicking the pre-pubertal state thus limiting the number of actively dividing cells and decreasing utero-ovarian perfusion which limits chemotherapy delivery to the ovaries [53]. However, its use for this indication remains controversial as human studies have shown inconsistent results $[25,54,55]$. As a result, it is not recommended as a standalone option to preserve fertility $[39 \bullet \bullet, 40 \bullet \bullet]$.

\section{Menstrual regulation and suppression}

In oncology patients, suppression of menses is mainly used to prevent anemia and thrombocytopenia, but can also be used to provide relief of menstrual-related symptoms. There may be a higher risk of heavy menstrual bleeding with hematologic malignancies or as a secondary effect of treatment that induces myelosuppression 
[56]. As such, menstrual regulation and/or suppression may be crucial. The overall aim of treatment is for a high efficacy option without causing harm.

\section{GnRH agonist}

GnRH agonists for the purpose of menstrual suppression are given as an injectable medication, which offer a high amenorrhea rate (73-97 \%) [57]. GnRH should only be given for a limited time during chemotherapy treatment and/or during the timeframe that the patient is at elevated risk for decreasing blood count secondary to treatment or malignancy. These medications have been proven to be superior to depot medroxyprogesterone acetate (DMPA) in preventing moderate to severe bleeding in young women undergoing myelosuppressive chemotherapy with subsequent severe thrombocytopenia [58]. In our practice, $11.25 \mathrm{mg}$ depot leuprolide is typically chosen and given every 8 to 12 weeks IM. Alternatively, if the patient is thrombocytopenic, leuprolide IV can be given daily until platelet counts are safe for an IM injection to be given.

Possible side effects of treatment are hot flushes, insomnia, joint pain, weight gain, and mood disturbance. The main risks of GnRH agonists are a decrease in bone mineral density (BMD) and local contusion or hematoma at the injection site. Patients should be offered add-back therapy with either norethindrone acetate 5 to $10 \mathrm{mg}$ daily or very low dose estradiol with progestin to prevent vasomotor symptoms and negative impact on BMD. Norethindrone acetate is a progestin with estrogenic action, which has been shown to be as effective as low-dose estradiol in prevention of decreased BMD and vasomotor symptoms. Add-back therapy can be started immediately or delayed for up to 6 months based on physician and patient preference, as well as clinical symptoms $[59,60]$.

\section{Progestin-only pills}

Progestin-only pills (POP) can be used to obtain menstrual lightening or suppression at variable rates. Low-dose POP (norethindrone $0.35 \mathrm{mg}$ ) can be given continuously for menstrual suppression; however, the rate of amenorrhea is low, reported around $10 \%$ [61]. High-dose POP is typically more effective in achieving complete menstrual suppression and amenorrhea can often be achieved within 1 week. However, unlike low-dose POP, high dose is associated with increased side effects such as acne, weight gain, headache, lipid profile changes, and mood disturbance. In our practice, we commonly utilize norethindrone acetate 5-20 mg daily, titrated for amenorrhea and side effect profile. Due to the need for daily oral medication, the success of this treatment relies on compliance. There are a few options for treatment regimens with high-dose progestin pills, including norethindrone acetate, medroxypro gesterone acetate, megestrol, and danazol.

\section{Depot medroxyprogesterone acetate}

This injectable hormonal contraceptive is a popular birth control method, which can also be used for menstrual lightening and amenorrhea. Rates of amenorrhea are about $50 \%$ after 1 year of use, though initial irregular vaginal bleeding is common [56, 62].

DMPA has some theoretical association with a possible increased risk of deep venous thrombosis and pulmonary embolism, although benefits usually outweigh this risk in women with active cancer [63]. However, patients with anemia and/or thrombocytopenia, due to their malignancy or chemotherapy regimen, may not tolerate initial irregular bleeding. Additionally, depending on the platelet levels, intramuscular injections may be contraindicated due to an elevated risk of hematoma formation.

\section{Combined hormonal contraception (pill, patch, ring)}

Combined hormonal contraceptives (CHC) can be taken in extended regimens skipping the hormone-free pills which are likely to result in amenorrhea. Greater than $80 \%$ of women report amenorrhea or infrequent menses after 1 year of use [64]. However, there is an increased risk of breakthrough bleeding (BTB) with extended use OCPs. Although combined oral contraceptives (COCs) have been used successfully for management of menses in cancer patients undergoing treatment, there is concern that in patients with malignancy, the estrogen contained in $\mathrm{CHC}$ may increase the risk of thromboembolic events [56, 65]. In addition, it is important to consider that some patients might experience nausea and emesis during the course of their malignancy and treatment, and CHC may exacerbate these symptoms leading to a need for discontinuation. 


\section{Levonorgestrel IUD for menstrual suppression}

The $52 \mathrm{mg}$ levonorgestrel IUD can be used for menstrual lightening and suppression. There is a $97 \%$ reduction in blood loss and complete menstrual suppression is noted in $50 \%$ of patients at 24 months of use [62,66]. There is an initial risk of light irregular menstrual bleeding for the first 3 to 6 months after insertion. If a patient has established menstrual lightening or suppression with a levonorgestrel IUD in place at the time of her diagnosis of malignancy, it is recommended to continue the device [56]. There is some controversy between physicians on the placement of a new device in patients with active disease due to concerns of infection. However, this has been found to be safe in other immunocompromised states such as autoimmune disease, organ transplant, and HIV.

\section{Contraception}

According to the 2013 National Youth Risk Behavior Survey, $47 \%$ of high school students in the USA admitted to previous sexual intercourse and of those, $14 \%$ did not use any method of pregnancy prevention [67]. An unintended pregnancy during cancer treatments may result in delay in therapy, teratogenic exposure, and/or pregnancy termination [3]. For many of these patients, unintended pregnancy is associated with an unacceptable health risk. Medically, these patients present increased challenges due to their underlying diagnoses and the increased risk of thrombotic disease associated with all malignancy. A thorough discussion of indicated contraceptive methods should be undertaken with each patient, with focus placed on efficacy and safety.

The Centers for Disease Control and Prevention adapted the World Health Organization (WHO) guidance to create the US Medical Eligibility Criteria (MEC) for Contraceptive Use, 2010, (with updates occurring in 2011 and 2012) for use by health care providers (WHO, CDC). It can be found in its complete form on the CDC website in the reproductive health section (www.cdc.gov/ reproductivehealth/UnintendedPregnancy/USMEC. $\mathrm{htm})[68,69]$. The US MEC ranks contraceptive methods based on a four-point scale from 1 (no restriction on use) to 4 (unacceptable health risk) for a large number of medical conditions, including certain malignancies [69]. Table 2 lists the contraceptive options and certain cancer-specific considerations [69-72].

\section{Survivorship care}

As discussed above, advancements in chemo- and radiotherapies revolutionized cancer treatment and improved long-term survival of cancer patients. Although many will experience long-standing diseasefree prognoses, many of these potent therapies can result in multiple short- and long-term adverse effects. The Children's Oncology Group (COG) has released evidence-based recommendations for screening and management of these late effects: COG Long-Term Follow-up Guidelines for Survivors of Childhood, Adolescent, and Young Adult Cancer (COG-LTFU Guidelines) [73]. Here, we focus on the guidelines for management of reproductive health which touch on concerns for hypogonadism, precocious puberty, reduced fertility potential, and sexual dysfunction [30].

\section{Hypogonadism}

The COG recommends counseling all girls/women regarding potential risk of POI. In the pre-pubertal patient, monitoring for signs of pubertal development is paramount. Evaluation should be initiated if pubertal development has not started by age 13 . LH, FSH, and estradiol levels should be obtained. In the pubertal patient, monitoring for menstrual irregularities in addition to sexual and pregnancy history is recommended. LH, FSH, and estradiol should be repeated for signs of estrogen deficiency or menstrual complications. Bone density screening and referral to endocrinology and/or gynecology in patients with signs of hypogonadism is necessary [30]. Treatment with hormone replacement therapy should be initiated if no pubertal development has started by age 13 and considered in patients with laboratory evidence of POI or without return to menses in 1 year.

\section{Precocious puberty}

The COG recommends yearly physical exam examinations should be completed until sexual maturity and includes Tanner staging and routine height/ weight evaluation. FSH, LH, estradiol, and bone age should be ordered with signs of early 


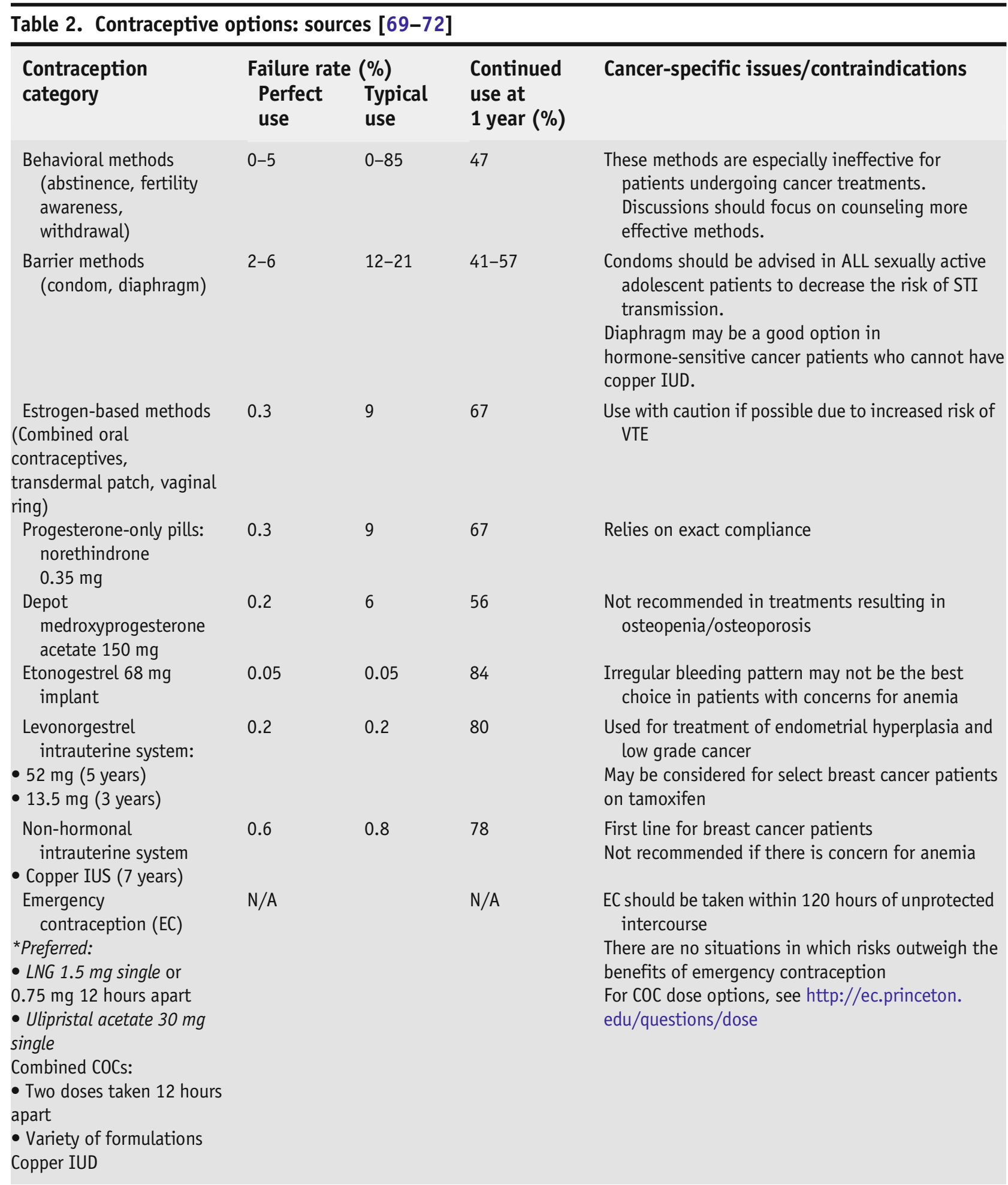


development along with referral to endocrinology. Pelvic ultrasound can be considered to rule out ovarian causes [30].

\section{Fertility/pregnancy concerns}

The best time to address concerns for future infertility is prior to oncologic treatment; however, in many cases, this is not fulfilled or patients who did receive counseling did not have adequate time or resources to complete preservation options before treatment onset [74, 75].

The presence or resumption of menses following cancer therapy does not ensure fertility and females who have sustained gonadotoxicity may still have regular menses [38]. As such, markers of fertility potential or ovarian reserve are used to predict the reproductive potential as a function of number and quality of remaining oocytes [6]. FSH + estradiol, anti-Müllerian hormone (AMH) and an ultrasound to assess antral follicle count are currently the tests recommended to assess ovarian reserve [6]. AMH has emerged as the most sensitive marker of ovarian reserve as levels do not fluctuate significantly during the menstrual cycle and it is useful in pre-pubertal girls [76]. Moreover, AMH has been shown to be a useful marker of damage to ovarian reserve as very low levels correlate with risk for ovarian failure after cancer therapy [77]. Although AMH shows great promise, it is not currently recommended in the COG guidelines [30]. There is a wide range of normal values in adult women and normative data in pediatric patients is limited.

For survivors who do show clinical and laboratory signs of POI, discussion should be undertaken regarding options of third party reproduction techniques (egg donation, surrogacy), adoption, and childless lifestyle. Unfortunately, in many areas, cancer survivors face challenges with exclusionary adoption policies due to their past medical history, and providers may be asked to provide documentation of disease-free survival time and expected lifespan [30].

Most survivors note a desire for future childbearing and endorse belief that their cancer experience will accentuate their parenting skills. However, many experience anxiety due to concerns of pregnancy complications and birth defects from their previous diagnosis and treatments [78]. Reports from the Childhood Cancer Survivorship Study and the Danish population found no association between parental mutagenic exposure (i.e., chemotherapy, irradiation to the gonads) and risk for congenital anomalies [79, 80]. Multiple studies have looked at future pregnancy outcomes of childhood cancer survivors. Although as a whole, pregnancy outcomes did not differ between survivors and control groups; patients with a history of abdominal and/or pelvic radiation showed higher rates of miscarriage, pre-term birth, stillbirth, and neonatal death that appear dose dependent and most likely due to uterine damage [78, 81-84].

\section{Sexual dysfunction}

Cancer and related treatment may predispose patients to sexual dysfunction; however, information regarding this in childhood cancer survivors is limited. Complications such as vulvar vaginal scarring from radiation damage and graft versus host disease, vestibular gland dysfunction from surgery and irradiation, and decreased hormonal function from ovarian damage are all possible causes of dyspareunia and sexual dysfunction in cancer survivors [25, 85]. Furthermore, depression and psychological dysfunction that may be seen in cancer survivors play a pivotal role in female sexual function $[30,86,87]$.

The COG recommends yearly assessment of sexual function and dyspareunia, inclusive of psychological evaluation, medication use, gynecologic concerns, and physical examination when appropriate. Standardized questionnaires such as the Female Sexual Function Index and Brief Index of Sexual Functioning may be helpful to elicit symptoms. Consider referral to gynecologist and/or psychologist for consultation and management as needed [30].

\section{Compliance with Ethical Standards}

Conflict of Interest

Gylynthia E. Trotman and Holly Hoefgen declare that they have no conflict of interest. 
Human and Animal Rights and Informed Consent

This article does not contain any studies with human or animal subjects performed by any of the authors.

\section{References and Recommended Reading}

Papers of particular interest, published recently, have been

highlighted as:

- Of importance

- Of major importance

1.• Howlader N, Noone AM, Krapcho M, Garshell et.al. (eds). SEER Cancer Statistics Review, 1975-2012, National Cancer Institute. Bethesda, MD, http://seer. cancer.gov/csr/1975_2012/, based on November 2014 SEER data submission, posted to the SEER web site, April 2015. Last accessed 8th Feb 2016.

This website gives the most uptodate information on cancer statitistics in the US.

2. Phillips SM, Padgett LS, Leisenring WM, Stratton KK, et al. Survivors of childhood cancer in the United States: prevalence and burden of morbidity. Cancer Epidemiol Biomarkers Prev. 2015;24(4):653-63.

3. Committee opinion no, 607. Gynecologic concerns in children and adolescents with cancer. Obstet Gynecol. 2014;124(2 Pt 1):403-8.

4. Gracia CR, Chang J, Kondapalli L, Prewitt M, et al. Ovarian tissue cryopreservation for fertility preservation in cancer patients: successful establishment and feasibility of a multidisciplinary collaboration. J Assist Reprod Genet. 2012;29:495-502.

5. Levine, J. Gonadotoxicity of cancer therapies in pediatric and reproductive-age females. In Oncofertility Medical Practice: Clinical Issues and Implementation (Gracia C, Woodruff T, eds.) 3-14 (Springer, 2012)

6. Committee opinion no. 618. Ovarian reserve testing. Obstet Gynecol. 2015;125(1):268-73.

7. Molina JR, Barton DL, Loprinzi CL. Chemotherapyinduced ovarian failure: manifestations and management. Drug Saf. 2005;28:401-16.

8. Green DM, Sklar CA, Boice Jr JD, Mulvihill JJ, et al. Ovarian failure and reproductive outcomes after childhood cancer treatment: results from the childhood cancer survivor study. J Clin Oncol. 2009;27:2374-81.

9. Sklar CA, Mertens AC, Mitby P, Whitton J, et al. Premature menopause in survivors of childhood cancer: a report from the childhood cancer survivor study. J Natl Cancer Inst. 2006;98:890-6.

10. Carel JC, Leger J. Precocious puberty. N Engl J Med. 2008;358:2366-77.

11. Fuqua JS. Treatment and outcomes of precocious puberty: an update. J Clin Endocrinol Metab. 2013;98(6):2198-207.

12. Rosenfield RL, Lipton RB, Drum ML. Thelarche, pubarche, and menarche attainment in children with normal and elevated body mass index. Pediatrics. 2009;123(1):84-8.

13. Herman-Giddens ME, Slora EJ, Wasserman RC, Bourdony CJ, et al. Secondary sexual characteristics and menses in young girls seen in office practice: a study from the Pediatric Research in Office Settings network. Pediatrics. 1997;99(4):505-12.

14. Midyett LK, Moore WV, Jacobson JD. Are pubertal changes in girls before age 8 benign? Pediatrics. 2003;111(1):47-51.

15. Berberoglu M. Precocious puberty and normal variant puberty: definition, etiology, diagnosis and current management. J Clin Res Pediatr Endocrinol. 2009; 1(4):164-74.

16. Burstein S. Growth disorders after cranial radiation in childhood. J Clin Endocrinol Metab. 1994;78:1280-1.

17. Ogilvy-Stuart AL, Clayton PE, Shalet SM. Cranial irradiation and early puberty. J Clin Endocrinol Metab. $1994 ; 78(6): 1282-6$.

18. Walvoord EC. The timing of puberty: is it changing? Does it matter? J Adolesc Health. 2010;47(5):433-9.

19. Carel JC, Eugster EA, Rogol A, Ghizzoni L, et al. Consensus statement on the use of gonadotropin-releasing hormone analogs in children. Pediatrics. 2009; 123:e752-62.

20. Ortmann O, Weiss JM, Diedrich K. Gonadotrophinreleasing hormone (GnRH) and GnRH agonists: mechanisms of action. Reprod Biomed Online. 2002;5 Suppl 1:1-7.

21. Hirsch HJ, Gillia D, Strich D, Chertin B, et al. The histerlin implant: a novel treatment for central precocious puberty. Pediatrics. 2005;116:e798-802.

22. Cafasso M, Elder DA, Blum S, Weis T et. al. Treatment of central precocious puberty using gonadotropinreleasing hormone agonists. J. Nurse Practitioners. 2015;11(7):686-94.

23. Klein K, Yang J, Aisenberg J, Wright $\mathrm{N}$ et.al. Efficacy and safety of triptorelin 6-month formulation in patients with central precocious puberty. J Pediatr Endocrinol Metab. 2016 Feb 17 [Epub ahead of print].

This recently published study discusses the potential benefits of a longer acting GnRHa in the treatment of CPP.

$24 . \bullet$ Lewis KA, Goldyn A, West KW, Eugster EA. A single histrelin implant is effective for 2 years for treatment of central precocious puberty. J Pediatr. 2013;163(4):1214-6.

This article has potential major implications for the longer use of the puberty suppressing implant.

25. Waimey KE, Smith BM, Confino R, Jeruss JS, et al. Understanding fertility in young female cancer 
patients. J Womens Health (Larchmt).

2015;24(10):812-8.

26. Palmert MR, Dunkel L, Clinical practice. Delayed puberty. N Engl J Med. 2012;366(5):443-53.

27. DiVasta AD, Gordon CM. Hormone replacement therapy for the adolescent patient. Ann N Y Acad Sci. 2008;1135:204-11.

28. Davenport ML. Moving toward an understanding of hormone replacement therapy in adolescent girls: looking through the lens of Turner syndrome. Ann N Y Acad Sci. 2008;1135:126-37.

29. Nelson LM. Clinical practice. Primary ovarian insufficiency. N Engl J Med. 2009;360:606-14.

30. Metzger ML, Meacham LR, Patterson B, Casillas JS, et al. Female reproductive health after childhood, adolescent, and young adult cancers: guidelines for the assessment and management of female reproductive complications. J Clin Oncol. 2013;31:1239-47.

31. Chemaitilly W, Mertens AC, Mitby P, Whitton J, et al. Acute ovarian failure in the childhood cancer survivor study. J Clin Endocrinol Metab. 2006;91(5):1723-8.

32. Cooper AR, Baker VL, Sterling EW, Ryan ME, et al. The time is now for a new approach to primary ovarian insufficiency. Fertil Steril. 2011;95(6):1890-7.

33. Committee opinion no. 605. Primary ovarian insufficiency in adolescents and young women. Obstet Gynecol. 2014;124(1):193-7.

34. van Kasteren YM, Schoemaker J. Premature ovarian failure: a systematic review on therapeutic interventions to restore ovarian function and achieve pregnancy. Hum Reprod Update. 1999;5(5):483-92.

35. Leader A, Lishner M, Michaeli J, Revel A. Fertility considerations and preservation in haemato-oncology patients undergoing treatment. Br J Haematol.

2011;15:291-308.

36. Green DM, Kawashima T, Stovall M, Leisenring W, et al. Fertility of female survivors of childhood cancer: a report from the childhood cancer survivor study. J Clin Oncol. 2009;27:2677-85.

37. Gilleland MJ, Elchuri SV, Vangile K, Wasilewski-Masker $\mathrm{K}$, et al. Perceptions of infertility risks among female pediatric cancer survivors following gonadotoxic therapy. J Pediatr Hematol Oncol. 2015;37(5):368-72.

38. Letourneau JM, Ebbel EE, Katz PP, Katz A, et al. Pretreatment fertility counseling and fertility preservation improve quality of life in reproductive age women with cancer. Cancer. 2012;118(6):1710-7.

39.• Loren AW, Mangu PB, Nohr Beck L, Brennan L, et al. Fertility preservation for patients with cancer: American Society of Clinical Oncology clinical practice guideline update. J Clin Oncol. 2013;31:2500-10.

This article gives guidance on up to date fertility preservation options for cancer patients and guidance on counseling.

40.• Ethics Committee of American Society for Reproductive Medicine. Fertility preservation and reproduction in patients facing gonadotoxic therapies: a committee opinion. Fertil Steril. 2013;100(5):1224-31.

This article gives guidance on up to date fertility preservation options for cancer patients and guidance on counseling.
41. Fallat ME, Hutter J. American Academy of Pediatrics Committee on Bioethics; American Academy of Pediatrics Section on Hematology/Oncology; American Academy of Pediatrics Section on Surgery. Preservation of fertility in pediatric and adolescent patients with cancer. Pediatrics. 2008;121(5):e1461-9.

42. Westphal LM, Massie JAM. Embryo and oocyte banking. In Oncofertility Medical Practice: Clinical Issues and Implementation. (Gracia C, Woodruff T, eds.) 5161 (Springer, 2012)

43. Mahajan N. Fertility preservation in female cancer patients: an overview. J Hum Reprod Sci. 2015;8:3-13.

44.• Cardozo ER, Thomson AP, Karmon AE, Dickinson KA, et al. Ovarian stimulation and in-vitro fertilization outcomes of cancer patients undergoing fertility preservation compared to age matched controls: a 17-year experience. J Assist Reprod Genet. 2015;32:587-96.

This article is useful and unique in that it address fertility preservation outcomes specifically in cancer survivors.

45. Practice Committees of American Society for Reproductive Medicine; Society for Assisted Reproductive Technology. Mature oocyte cryopreservation: a guideline. Fertil Steril. 2013;99(1):37-43.

46. Noyes N, Labella PA, Grifo J, Knopman JM. Oocyte cryopreservation: a feasible fertility preservation option for reproductive age cancer survivors. J Assist Reprod Genet. 2010;27(8):495-9.

47. Salama M, Woodruff TK. New advances in ovarian autotransplantation to restore fertility in cancer patients. Cancer Metastasis Rev. 2015;34(4):807-22.

48. Oktay K, Sonmezer M. Ovarian tissue banking for cancer patients: fertility preservation, not just ovarian cryopreservation. Hum Reprod. 2004; 19:477-80.

49. Radford JA, Lieberman BA, Brison DR, Smith AR, et al. Orthotopic reimplantation of cryopreserved ovarian cortical strips after high-dose chemotherapy for Hodgkin's lymphoma. Lancet. 2001;357(9263):11725.

50. Practice Committee of American Society for Reproductive Medicine. Ovarian tissue cryopreservation: a committee opinion. Fertil Steril. 2014;101(5):123743.

This article is useful for information on OTC.

51. Uzelac P. Christensen G, Nakajima S. The role of invitro maturation in fertility preservation. In Oncofertility Medical Practice: Clinical Issues and Implementation. (Gracia C, Woodruff T, eds.) 77-89 (Springer, 2012).

52. Knopman JM, Noyes N. Mitigating the risk: The role of ovarian transposition and ovarian suppression. In Oncofertility Medical Practice: Clinical Issues and Implementation. (Gracia C, Woodruff T, eds.) 91-104 (Springer, 2012).

53. Blumenfeld Z, von Wolff M. GnRH-analogues and oral contraceptives for fertility preservation in women during chemotherapy. Hum Reprod Update.

2008;14(6):543-52.

54. Del Mastro L, Ceppi M, Poggio F, Bighin C, et al. Gonadotropin-releasing hormone analogues for the 
prevention of chemotherapy-induced premature ovarian failure in cancer women: systematic review and meta-analysis of randomized trials. Cancer Treat Rev. 2014;40(5):675-83.

55. Turner NH, Partridge A, Sanna G, Di Leo A, et al. Utility of gonadotropin-releasing hormone agonists for fertility preservation in young breast cancer patients: the benefit remains uncertain. Ann Oncol.

2013;24(9):2224-35.

56. Committee opinion no. 606. Options for prevention and management of heavy menstrual bleeding in adolescent patients undergoing cancer treatment. Obstet Gynecol. 2014;124(2 Pt 1):397-402.

57. Quaas AM, Ginsburg ES. Prevention and treatment of uterine bleeding in hematologic malignancy. Eur J Obstet Gynecol Reprod Biol. 2007;134(1):3-8.

58. Meirow D, Rabinovici J, Katz D, Or R, et al. Prevention of severe menorrhagia in oncology patients with treatment-induced thrombocytopenia by luteinizing hormone-releasing hormone agonist and depomedroxyprogesterone acetate. Cancer. 2006;107(7):1634-41.

59. Friedman AJ, Daly M, Juneau-Norcross M, Gleason R, et al. Long-term medical therapy for leiomyomata uteri: a prospective, randomized study of leuprolide acetate depot plus either oestrogen-progestin or progestin 'add-back' for 2 years. Hum Reprod.

1994;9(9):1618-25.

60. Divasta AD, Laufer MR, Gordon CM. Bone density in adolescents treated with a GnRH agonist and add-back therapy for endometriosis. J Pediatr Adolesc Gynecol. 2007;20(5):293-7.

61. Black A, Francoeur D, Rowe T, Collins J, et al. Canadian contraception consensus. J Obstet Gynaecol Can. 2004;26(4):347-87. 389-436.

62. Hubacher D, Lopez L, Steiner MJ, Dorflinger L. Menstrual pattern changes from levonorgestrel subdermal implants and DMPA: systematic review and evidencebased comparisons. Contraception. 2009;80(2):113-8.

63. ACOG Practice Bulletin No. 110. Noncontraceptive uses of hormonal contraceptives. Obstet Gynecol. 2010;115(1):206-18.

64. Miller L, Hughes JP. Continuous combination oral contraceptive pills to eliminate withdrawal bleeding: a randomized trial. Obstet Gynecol. 2003;101(4):653-61.

65. Amsterdam A, Jakubowski A, Castro-Malaspina H, Baxi $\mathrm{E}$, et al. Treatment of menorrhagia in women undergoing hematopoietic stem cell transplantation. Bone Marrow Transplant. 2004;34(4):363-6.

66. Andersson J, Rybo G. Levonorgestrel-releasing intrauterine device in the treatment of menorrhagia. $\mathrm{Br} \mathrm{J}$ Obstet Gynaecol. 1990;97(8):690-4.

67. Brener ND, Kann L, Shanklin S, et al. Methodology of the Youth Risk Behavior Surveillance System-2013. MMWR Cen Dis Control. 2013;62(RR-1):1-20.

68. WHO. Medical eligibility for contraceptive use. 4 th ed Geneva; 2009

69. U S. Medical Eligibility Criteria for Contraceptive Use, 2010. MMWR recommendations and reports: morbidity and mortality weekly report recommendations and reports. MMWR Cen Dis Control. 2010;59(RR-4):1-86.

70. Society for Adolescent Health and Medicine. Emergency contraception for adolescents and young adults: guidance for health care professionals. J Adolesc Health. 2016;58(2):245-8.

71. Practice Bulletin No 152. Emergency contraception. Obstet Gynecol. 2015;126(3):e1-11.

72. Trussell J. Choosing a contraceptive: efficacy, safety and personal considerations. In Contraceptive Technology 19th Ed. (Hatcher R, Trussell J et al. eds) 19-47 (Ardent Media, 2007)

73. Children's Oncology Group: Long Term Follow-Up Guidelines for Survivors of Childhood, Adolescent and Young Adult Cancer. October 2013; Version 4.0: Available from: www.survivorshipguidlines.org. Last accessed 21st Jan 2016

74. Deshpande NA, Braun IM, Meyer FL. Impact of fertility preservation counseling and treatment on psychological outcomes among women with cancer: a systematic review. Cancer. 2015;121(22):3938-47.

75. Bann CM, Treiman K, Squires L, Tang J, et al. Cancer survivors' use of fertility preservation. J Womens Health (Larchmt). 2015;24(12):1030-7.

76. Peigné $M$, Decanter $C$. Serum AMH level as a marker of acute and long-term effects of chemotherapy on the ovarian follicular content: a systematic review. Reprod Biol Endocrinol. 2014;12:26.

77. Brougham MF, Crofton PM, Johnson EJ, Evans N, Anderson RA, Wallace WH. Anti-Müllerian hormone is a marker of gonadotoxicity in pre- and postpubertal girls treated for cancer: a prospective study. J Clin Endocrinol Metab. 2012;97(6):2059-67.

78. Gawade PL, Oeffinger KC, Sklar CA, Green DM, et al. Lifestyle, distress, and pregnancy outcomes in the Childhood Cancer Survivor Study cohort. Am J Obstet Gynecol. 2015;212(1):47.e1-10.

79. Signorello LB, Mulvihill JJ, Green DM, Munro HM. Congenital anomalies in the children of cancer survivors: a report from the childhood cancer survivor study. J Clin Oncol. 2012;30(3):239-45.

80. Winther JF, Olsen JH, Wu H, Shyr Y, et al. Genetic disease in the children of Danish survivors of childhood and adolescent cancer. J Clin Oncol. 2012;30(1):27-33.

81. Lie Fong S, van den Heuvel-Eibrink MM, Eijkemans MJ, Schipper I, et al. Pregnancy outcome in female childhood cancer survivors. Hum Reprod. 2010;25(5):1206-12.

82. Green DM, Whitton JA, Stovall M, Mertens AC, et al. Pregnancy outcome of female survivors of childhood cancer: a report from the Childhood Cancer Survivor Study. Am J Obstet Gynecol. 2002;187(4):1070-80.

83. Signorello LB, Cohen SS, Bosetti C, Stovall M, et al. Female survivors of childhood cancer: preterm birth and low birth weight among their children. J Natl Cancer Inst. 2006;98(20):1453-61. 
84. Signorello LB, Mulvihill JJ, Green DM, Munro HM, et al. Stillbirth and neonatal death in relation to radiation exposure before conception: a retrospective cohort study. Lancet. 2010;376(9741):624-30.

85. Schover LR, van der Kaaij M, van Dorst E, Creutzberg C, et al. Sexual dysfunction and infertility as late effects of cancer treatment. EJC Suppl. 2014;12(1):41-53.
86. Bober SL, Zhou ES, Chen B, Manley PE, et al. Sexual function in childhood cancer survivors: a report from project REACH. J Sex Med. 2013;10:2084-93.

87. Zebrack BJ, Foley S, Wittmann D, Leonard M. Sexual functioning in young adult survivors of childhood cancer. Psychooncology. 2010;19:814-22. 